\title{
Effect of educational intervention on knowledge, attitude and consumption of fast food among adolescents
}

\author{
Shiv Kumar Yadav', Bhola Nath,"* \\ ${ }^{1}$ Assistant Professor, ${ }^{2}$ Professor and Head, Community Medicine, Govt. Doon Medical College, Dehradun, Uttarakhand, India
}

*Corresponding Author

Email: bholanath2001@gmail.com

\begin{abstract}
Introduction: Fast food are being routinely consumed worldwide as they can be prepared and served very quickly. Although the list of food items which comes under category of fast food is long, but burger, carbonated beverages, French fries, cakes, pastries and pizza are most commonly consumed fast food items. Fast food items are having high fat content, low fiber and nutrients and their excess consumption causes obesity.

Objective: Assessment of effect of Educational intervention on knowledge, attitude and consumption of fast food among adolescents.

Methodology: Cross sectional study conducted on 100 adolescents. Initially pre tested questionnaire was used to assess baseline knowledge, attitude and utilisation of junk food, followed by educational intervention in form of a lecture by a power point presentation and then again same questionnaire was given to student next day to assess the effect of intervention. Data entry and analysis was done \& Chi-Square test was applied to know the effect of intervention.

Result: Educational intervention led to significant change in the knowledge about the adverse effect of fast food which was increased from $49 \%$ to $71 \%$ as well as adolescents preference for eating fast food reduced from $73 \%$ to $49 \%$. Attitude towards non consumption of fast food was significantly changed as there was increase in number of students started bringing home prepared food in lunch boxes from $36 \%$ to $57 \%$.

Conclusion: Education intervention brings significant change in knowledge, attitude and consumption of fast food among adolescents and similar kind of intervention at regular interval will play a crucial role in preventing life style related disease among future generations.
\end{abstract}

Keywords: Adolescent, Fast food, Knowledge.

\section{Introduction}

Day by day innovations are being carried out to make faster transportation, faster communication, faster computers, faster music, and to provide faster services. This kind of time bound attitude ultimately affected our dietary habits also and gave rise to fast food. Fast food items as the name suggests are prepared fresh, hot and served fast. Fast food items are also known as quickservice food as these items are routinely sold and delivered in an amount of time ranging from a few seconds to several minutes. Fast food items appeal by being fatty, low in fiber and nutrients. Burgers and French fried potatoes, carbonated beverages are most commonly identified fast food items among population, but the list of items sold in fast food category is increasing day by day. Fried fish and shellfish, hot dogs, chicken, pizza, roast beef, pasta, salty French fries, beef burgers, fried chicken, and pizzas with a thick cheese covering are some of commonly consumed fast food items among people. Fast food has become a prominent feature of the diet of children and young adults throughout the world and increasing day by day. ${ }^{1}$ In United States, Since 1970s Consumption of fast food has increased rapidly ${ }^{2}$ among adolescents from all socioeconomic and racial/ethnic groups ${ }^{1,3}$ and $75 \%$ of adolescents eats fast food 1 or more times per week ${ }^{4}$ which can be well proved by the fact that there was huge increase in sales of fast food to $\$ 161$ billion in 2004, of which burgers accounted for 53\%. ${ }^{5}$ Today in the United States, up to $37 \%$ of adults and up to $42 \%$ of children regularly consume fast food which means they have higher intakes of energy, fat, saturated fat, sodium, and carbonated soft drinks. ${ }^{1,6,7}$ Various studies and trials have also indicated that frequent consumption of fast food leads to increase risk of cardiovascular disease (CVD) as fast food has been shown to promote weight gain and insulin resistance ${ }^{8}$ Eating habits of fast food among adolescent have evolved due to their rich fat content, high palatability, easy availability and time pressure exerted on students as students need something which they can get fast and consume fast so they can have more time for work. Unhealthy eating habits (consumption of fast food) seriously affect physical, mental and social wellbeing of the individual. ${ }^{8}$ Therefore this study is conducted to assess the effect of educational intervention on Knowledge, attitude and consumption of fast food among adolescents.

\section{Aims and Objectives}

1. To document the baseline knowledge, attitude and consumption practices of fast food among adolescents

2. To assess effect of an educational intervention on their pre-existing knowledge, attitude and consumption practices of fast food. 


\section{Methodology}

A descriptive, cross-sectional study was conducted among adolescent school students of $9^{\text {h }}$ class of a private school of North India. Total study participants were 100. Informed consent was taken before enrolment of participants. Study was carried in 2 parts, firstly baseline knowledge of students was assessed using a validated and pre-tested questionnaire designed to measure knowledge, attitude and consumption of fast food by students, followed by an educational intervention in form of a power point presentation of 1 hour duration on fast food and on next day the same questionnaire was given to them to assess their improvement in pre-existing knowledge, attitude and consumption practices of fast food.

Study Tool: Validated and pre-tested questionnaire was used which mainly focused on the assessment of knowledge attitude and consumption of fast food by students.

Data Analysis: The data was entered and interpreted using SPSS software. The frequencies and percentages were calculated for the categorical responses. The Chisquared test with $95 \%$ confidence interval was applied to see whether there was any statistical difference between the knowledge of the adolescent before and after educational intervention, for all the tests p-value $<0.05$ was considered significant.

\section{Result}

Effects of Educational intervention on Knowledge about Fast Food: Among study participants 56 were male and 44 female, belonging to age group of 12-15 years. Fast food is considered as a substitute for proper meal among adolescents but educational intervention brought up significant change in their opinion ( $\mathrm{p}$ value0.00196 ) as shown in Table 1 . Knowledge about the addictive nature of fast food and its role in causation of obesity also underwent a significant improvement after education intervention. Educational intervention also brought up a significant change in their knowledge regarding role of excessive consumption of candies in causation of dental caries awareness about adverse effects on health due to excessive consumption of fast food was only present among $49 \%$ adolescents and post intervention $71 \%$ adolescent became aware about it $(\mathrm{p}$ value-0.0014) as shown in Table 1. It was also found that only $54 \%$ of students thought that fast food is harmful but after intervention it was significantly increased to $78 \%$. Both the differences were found to be significant ( $p$ value-0.0001). Awareness gap was also present regarding consumption of soft drink although only $13 \%$ used to believe that it is safe and healthy to consume it but this knowledge improved post intervention and only $3 \%$ were left with ignorance that soft drink consumption is healthy. It was also observed that only $29 \%$ of students were aware that soft drink causes osteoporosis but after intervention knowledge was increased to $52 \%$ and the difference was found to be significant as shown in graph 1. Excessive consumption of chocolate is a very common practice among children and adolescents and awareness about it harmful effect have increased among population since many years. However initially $17 \%$ participants were still having false belief that there is no harmful effect of excessive consumption of chocolates but awareness improved after intervention as shown in graph 2.

Table 1: Effects of educational intervention on knowledge about fast food

\begin{tabular}{|c|c|c|c|}
\hline Knowledge Variables & Pre Intervention $(\mathrm{n}=\mathbf{1 0 0})$ & Post Intervention $(\mathrm{n}=\mathbf{1 0 0})$ & Chi square, (P-value) \\
\hline \multicolumn{4}{|c|}{ Fast food as substitute of proper meal } \\
\hline No & 66 & 79 & \multirow{4}{*}{$14.84,(0.001960$} \\
\hline Yes & 1 & 7 & \\
\hline Not sure & 22 & 12 & \\
\hline Don't know & 11 & 2 & \\
\hline \multicolumn{4}{|c|}{ Fast food Cause Addiction } \\
\hline Yes & 44 & 59 & \multirow{4}{*}{$5.8,(0.122)$} \\
\hline No & 16 & 16 & \\
\hline May be & 32 & 19 & \\
\hline Don't know & 8 & 6 & \\
\hline \multicolumn{4}{|c|}{ Fast food Relation with Obesity } \\
\hline Yes & 55 & 69 & \multirow{4}{*}{$6.05,(0.108)$} \\
\hline No & 8 & 7 & \\
\hline May Be & 20 & 17 & \\
\hline Don't Know & 17 & 7 & \\
\hline \multicolumn{4}{|c|}{ Knowledge regarding candies } \\
\hline Dental caries & 71 & 87 & \multirow{4}{*}{$7.8,(0.05)$} \\
\hline Beneficial & 6 & 3 & \\
\hline $\begin{array}{l}\text { Neither beneficial nor } \\
\text { harmful }\end{array}$ & 8 & 4 & \\
\hline Don't know & 15 & 6 & \\
\hline
\end{tabular}




\begin{tabular}{|c|c|c|c|}
\hline \multicolumn{4}{|c|}{ Whether any adverse effects associated with fast food } \\
\hline Yes & 49 & 71 & \multirow{2}{*}{$10.08,(0.0014)$} \\
\hline No & 51 & 29 & \\
\hline \multicolumn{4}{|c|}{ Knowledge about harmful effect of Fast food } \\
\hline Harmful & 28 & 55 & \multirow{4}{*}{$20.5,(0.0001)$} \\
\hline $\begin{array}{l}\text { No problem once a } \\
\text { month }\end{array}$ & 26 & 23 & \\
\hline Harmful but eat & 45 & 19 & \\
\hline Not harmful & 1 & 3 & \\
\hline
\end{tabular}

Graph 1: Effect of intervention on knowledge related to soft drinks consumption (n=100)*

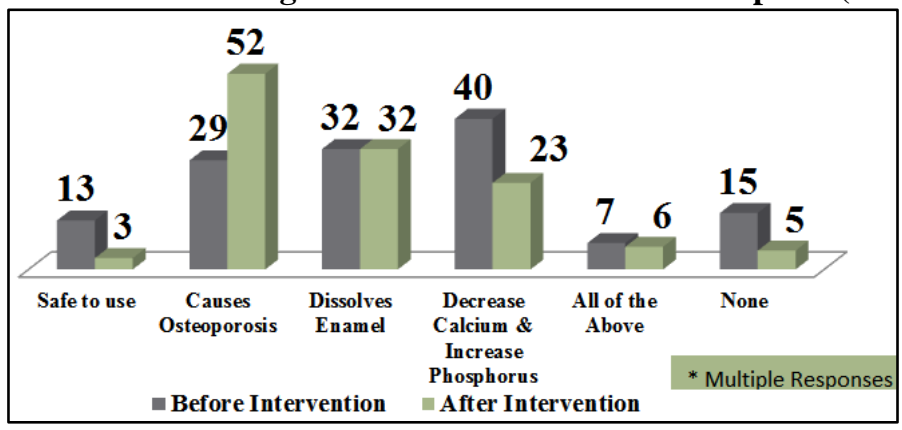

Graph 2: Effect of intervention on knowledge regarding chocolates $(\mathbf{n}=100)$ *

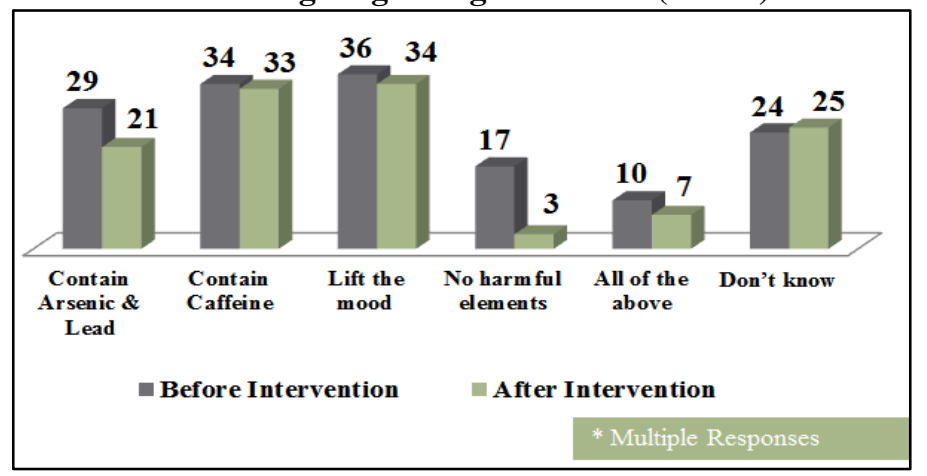

Effects of Educational Intervention on the Attitude of Students Regarding Fast Food: It is well known worldwide that children and adolescents like's fast food a lot which was also elicited in baseline assessment and it was found that $73 \%$ likes to consume fast food but this attitude underwent a significant change by educational intervention and post intervention assement revealed that only $49 \%$ will like to consume fast food in future ( $p$ value- 0.0005). Consumption of fast food is also dependent on attitude of adolescent that they consider it is an alternative to fruits and vegetables which was also elicited as $36 \%$ of adolescent could not deny about this attitude but this was significantly reduced to $17 \%$ (P value-0.009). Fast food advertisement has a strong relation with their increased consumption as documented by $61 \%$ of students during baseline assessment and this belief was significantly increased to $87 \%$ after intervention ( $\mathrm{p}$ value-0.000102) as shown in Table 2.

Table 2: Effects of Educational intervention on attitude of students regarding fast food

\begin{tabular}{|c|c|c|c|c|}
\hline \multicolumn{2}{|c|}{ Attitude related variables } & Pre Intervention $(\mathrm{n}=\mathbf{1 0 0})$ & Post Intervention $(\mathrm{n}=\mathbf{1 0 0})$ & Chi square, (P-value) \\
\hline \multicolumn{5}{|c|}{\begin{tabular}{|c|} 
Likeness of fast food \\
\end{tabular}} \\
\hline \multicolumn{2}{|l|}{ Yes } & 73 & 49 & \multirow{2}{*}{$12.11,(0.0005)$} \\
\hline \multicolumn{2}{|l|}{ No } & 27 & 51 & \\
\hline \multicolumn{5}{|c|}{ Type of evening snacks } \\
\hline \multirow[t]{2}{*}{ Healthy } & Fresh fruits & 63 & 50 & \multirow{6}{*}{$0.35,(0.55)$} \\
\hline & Soup & 5 & 13 & \\
\hline \multirow{4}{*}{$\begin{array}{l}\text { Non } \\
\text { healthy }\end{array}$} & Candy bar & 8 & 6 & \\
\hline & Chips & 6 & 13 & \\
\hline & Others & 13 & 8 & \\
\hline & Don't have & 5 & 10 & \\
\hline
\end{tabular}




\begin{tabular}{|c|c|c|c|}
\hline \multicolumn{4}{|c|}{ Intake of fast food } \\
\hline Taste & 82 & 66 & \multirow{5}{*}{$8.47,(0.07)$} \\
\hline Easily available & 6 & 9 & \\
\hline Busy schedule & 5 & 6 & \\
\hline Any other reason & 3 & 5 & \\
\hline Don't take & 4 & 14 & \\
\hline \multicolumn{4}{|c|}{ Alternative to fresh fruits \& vegetables } \\
\hline No & 64 & 83 & \multirow{3}{*}{$9.30,(0.009)$} \\
\hline Yes & 18 & 8 & \\
\hline Don't Know & 18 & 9 & \\
\hline \multicolumn{4}{|c|}{ Fast food advertisement } \\
\hline $\begin{array}{l}\text { Strong relation with fast food } \\
\text { consumption }\end{array}$ & 34 & 55 & \multirow{3}{*}{$18.37,(0.000102)$} \\
\hline $\begin{array}{l}\text { little relation with fast food } \\
\text { consumption }\end{array}$ & 27 & 32 & \\
\hline No relation & 39 & 13 & \\
\hline
\end{tabular}

Effects of Educational Intervention on Fast Food Consumption Practices among Students: Most of the adolescents prefer to eat fast food from canteen during lunch break and avoids bringing lunch box from home as evident by finding that $36 \%$ of students brought their lunch boxes during baseline assessment but after intervention 57\% student brought home cooked food in their lunch box ( $\mathrm{p}$ value-0.0016) as shown in Table 3 . There was a significant decline in the frequency of fast food consumption among students as $51 \%$ of students used to consume fast food more than twice a week but after intervention only $33 \%$ indulged in this practice (p value-0.037).Similarly percentage of students who have stopped the soft drinks consumption increased from $9 \%$ to $25 \%$ (p value-0.007). It was observed that gratification of hunger instantly was main reason for consumption of fast food as documented by $86 \%$ of participants but after intervention this practices was reduced and $32 \%$ students documented that they will not consume it on regular basis ( $p$ value- 0.037). Practice of eating fruits was improved as $53 \%$ of students who do not used to consume fruit which reduced to $2 \%$ and $49 \%$ of students started consuming it more than 5 times a week ( $p$ value-0.00001). Similarly frequency of fruit juice consumption also improved ( $p$ value-0.0105) shown in Table 3.This Study also tried to find the moments where excess consumption of fast food takes place and it was found that when adolescents are watching TV or during school time in lunch break from school cafeteria. Education intervention brought up a change in these practices as shown in Graph 3.

Table 3: Effects of educational intervention on fast food consumption practices

\begin{tabular}{|c|c|c|c|}
\hline & Pre Intervention $(n=100)$ & $\begin{array}{c}\text { Post Intervention } \\
(\mathbf{n}=100)\end{array}$ & Chi square (P- value) \\
\hline \multicolumn{4}{|c|}{ Practice related variables Brought lunch box on the day of survey } \\
\hline Yes & 36 & 57 & \multirow{2}{*}{$9.915,(0.0016)$} \\
\hline No & 64 & 43 & \\
\hline \multicolumn{4}{|c|}{ Lunch box frequency } \\
\hline Daily & 36 & 47 & \multirow{3}{*}{$2.56,(0.276)$} \\
\hline $3-4$ times & 19 & 17 & \\
\hline Don't bring & 45 & 36 & \\
\hline \multicolumn{4}{|c|}{ Fast Food frequency } \\
\hline Don't take & 7 & 13 & \multirow{5}{*}{$10.19,(0.037)$} \\
\hline$\leq$ once /week & 42 & 54 & \\
\hline $2-3$ times/week & 32 & 22 & \\
\hline 3-5times/week & 16 & 6 & \\
\hline$>5$ times/ week & 3 & 5 & \\
\hline \multicolumn{4}{|c|}{ Eat when not hungry } \\
\hline Never & 14 & 32 & \multirow{3}{*}{$9.64,(0.008)$} \\
\hline Some times & 83 & 64 & \\
\hline Always & 3 & 4 & \\
\hline \multicolumn{4}{|c|}{ Soft drink frequency } \\
\hline Don't take & 9 & 25 & \multirow{5}{*}{$13.87,(0.007)$} \\
\hline$\leq 1 /$ week & 46 & 41 & \\
\hline 2-3/week & 24 & 26 & \\
\hline 3-4/week & 14 & 6 & \\
\hline$>5 /$ week & 7 & 2 & \\
\hline
\end{tabular}




\begin{tabular}{|l|c|c|c|}
\hline \multicolumn{3}{|c|}{ Fruits frequency } \\
\cline { 1 - 3 }$>5 /$ week & 26 & 49 & \multirow{2}{*}{$65.8,(0.00001)$} \\
\hline$\leq 1 /$ week & 2 & 7 & \\
\hline $2-3 /$ week & 6 & 14 & \multirow{2}{*}{$13.15,(0.0105)$} \\
\hline $3-5 /$ week & 13 & 28 & \\
\hline Don't take & 53 & 2 & \\
\hline \multicolumn{2}{|c|}{ Fresh fruits juice frequency } \\
\hline$>5 /$ week & 14 & 30 & \\
\hline$\leq 1 /$ week & 28 & 35 & \\
\hline $2-3 /$ week & 32 & 10 & \\
\hline $3-5 /$ week & 20 & 9 & \\
\hline Don't take & 6 & & \\
\hline
\end{tabular}

Graph 3: Effect of Intervention on practices of fast food consumption $(n=100) *$

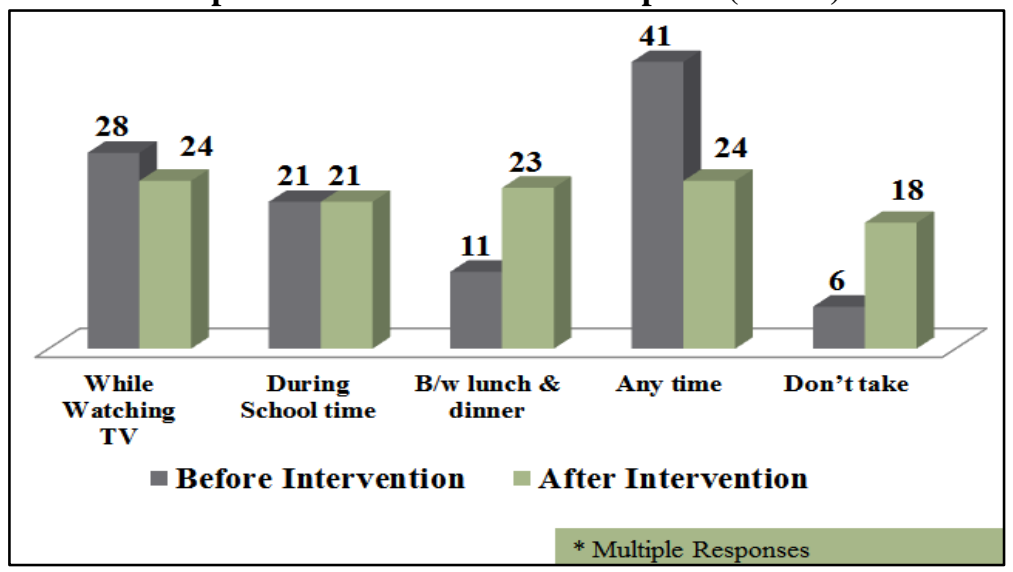

\section{Discussion}

It is a well-known finding that fast food consumption is associated with higher total energy intake and poorer diet quality among adolescents in a metropolitan cities. ${ }^{9}$ Adolescent girls who consumes fast food 4 times a week acquires more total energy when compared with those who do not ${ }^{10}$ Fast-food consumption was found to be significant predictor of dietary fat among girls as compared to boys. ${ }^{11}$ Consumption of fast food among children accumulates an average of $187 \mathrm{kcal} /$ day more than those who did not. It has been scientifically proved that the possibility of becoming obese over next 15 -year period increased by $86 \%$ among those young white adults who visited fast-food restaurants more than twice per week as compared with those visited less than once per week, after adjustment for potential confounders. Fast food consumption (cheeseburgers, french-fried potatoes, sugar-sweetened beverages, etc.) leads to increase in dietary intake of more total and saturated fat, more total carbohydrate and added sugars, less dietary fibre, and more energy per gram of solid food. ${ }^{12}$ The high energy density and palatability of fat may promote excess energy intake. ${ }^{13}$ In this study baseline knowledge regarding considering fast food as a substitute for proper meal was significantly changed after education intervention among adolescent ( $p$ value-0.00196). Significant increase in the Knowledge of the students about the adverse effect of fast food was observed which was $49 \%$ before intervention and increased to $71 \%$ after intervention ( $\mathrm{P}$ value-0.0014). Fast food advertisement has a relation with increased fast food consumption as per opinion of $61 \%$ of students which significantly improved to $87 \%$ after intervention. ( $P$ value-0.000102) Fast food consumption is maximum among adolescent age group. ${ }^{14}$ The workforce at fast food restaurants is mainly adolescents 1 who receive discounted or free food as part of their compensation. ${ }^{9}$ Since youth are more easily influenced by advertisements, the fast food industry targets heavily towards children with the aim of inculcating a fast-food consumption habit can be carried forward into adulthood. ${ }^{15}$ There was significant improvement in consumption of fruits ( $p$ value-0.00001) and fruit juice ( $p$ value-0.0105) after educational intervention. Fruits and non starchy vegetables protects against excessive weight gain as they contains low energy density, high fiber content, and low glycemic index and inadequate consumption of fruits and vegetables is associated with obesity-related morbidities such as cardiovascular disease $^{16,17}$ and diabetes. ${ }^{18}$ This study elicited a major finding that baseline assessment revealed $73 \%$ of adolescent used to like fast food but after educational intervention their attitude significantly changed and it was reduced to $49 \%$ ( $p$ value- 0.0005 ). Initially only $54 \%$ adolescent used to believe that Fast food consumption is harmful but educational intervention significantly improved their knowledge and $78 \%$ 
considered it is harmful for health. ( $p$ value-0.0001). It was observed that gratification of hunger instantly was main reason for consumption of fast food as documented by $86 \%$ of participants.

Educational intervention brought up a significant decline in the frequency of fast food consumption among students as initially $51 \%$ of students used to consume fast food more than twice a week but after intervention only $33 \%$ indulged in this practice.(p value-0.037) There was significant improvement in students who stopped consuming soft drinks from $9 \%$ to $25 \%$ ( $\mathrm{p}$ value-0.007). School cafeterias are also responsible for increasing trend of fast food consumption. $^{14,19}$ as seen in this study majority of students used to consume fast food available at school cafeteria during lunch break and stopped the healthy habit of bring home cooked food in their lunch boxes. Therefore intervention needs to be done by school and college administrative authorities to limit the sale of fast food in the premises so that fast food consumption can be limited among adolescents and youth.

\section{Conclusion}

Educational intervention brought up statistical significant increase in knowledge about fast food and change in attitude and consumption practices of food food among adolescents. Similar interventions are needed to increase the awareness related to various health related topics.

\section{Limitation of the Study}

Since this study was conducted on a small sample size and on urban adolescents so study findings will vary with those of adolescent's residing in rural area.

\section{References}

1. Shanthy A. Bowman, Steven L. Gortmaker, Cara B. Ebbeling, Mark A. Pereira, David S. Ludwig. Effects of fast food consumption on energy intake and diet quality among children in a national household survey. Official journal of the American academy of pediatrics. 2004. Vol.113:112-118.

2. Guthrie JF, Lin B-H, Frazao E. Role of food prepared away from home in the American diet, 1977-78 versus 1994-96: changes and consequences. J Nutr Educ Behav. 2002;34:140-150.

3. Nielsen SJ, Siega-Riz AM, Popkin BM. Trends in food locations and sources among adolescents and young adults. Prev Med. 2002;35:107-113.

4. Story M, Neumark-Sztainer D, French S. Individual and environmental influences on adolescent eating behaviors. $J$ Am Diet Assoc. 2002;102:S40-S51.

5. Fast food in the USA. Internet: http://www.euromonitor.com/reportsummary.aspx? folder_Fast_food_in_the_USA\& industry folder_Catering_and_vending (accessed 12 December 05).

6. Paeratakul S, Ferdinand DP, Champagne CM, Ryan DH, Bray GA. Fast-food consumption among US adults and children: dietary and nutrient intake profile. J Am Diet Assoc 2003;103(10):1332- 8 .
7. Nielsen SJ, Siega-Riz AM, Popkin BM. Trends in energy intake in U.S. between 1977 and 1996: similar shifts seen across age groups. Obes Res 2002;10(5):370-8.

8. Pereira MA, Kartashov AI, Ebbeling CB, et al. Fast-food habits, weight gain, and insulin resistance (the CARDIA study): 15-year prospective analysis. Lancet 2005;365:36-42.

9. French SA, Story M, Neumark-Sztainer D, Fulkerson JA, Hannan P. Fast food restaurant use among adolescents: associations with nutrient intake, food choices and behavioral and psychosocial variables. Int $J$ Obes. 2001;25:1823-1833.

10. McNutt SW, Hu Y, Schreiber GB, Crawford PB, Obarzanek E, Mellin L.A longitudinal study of the dietary practices of black and white girls 9 and 10 years old at enrollment: the NHLBI Growth and Health Study. $J$ Adolesc Health. 1997;20:27-37.

11. Cusatis DC, Shannon BM. Influences on adolescent eating behavior. J Adolesc Health. 1996;18:2.

12. Subar AF, Krebs-Smith SM, Cook A, Kahle LL. Dietary sources ofnutrients among US Children, 1989-1991. Pediatrics. 1998;102:913-923.

13. Rolls BJ. The role of energy density in the overconsumption of fat. J Nutr. 2000;130:268S-271S734.

14. Nestle M. Food Politics: How the Food Industry Influences Nutrition and Health. Berkeley, CA: University of California Press; 2002.

15. McNeal JU. Tapping the three kids' markets. Am Demogr. 1998;20:37-41.

16. Bazzano LA, He J, Ogden LG, et al. Fruit and vegetable intake and risk of cardiovascular disease in US adults: the first National Health and Nutrition Examination Survey Epidemiologic Follow-up Study. Am J Clin Nutr. 2002;76:93-99.

17. Joshipura KJ, Hu FB, Manson JE, et al. The effect of fruit and vegetable intake on risk for coronary heart disease. Ann Intern Med. 2001;134:1106-1114.

18. Ford ES, Mokdad AH. Fruit and vegetable consumption and diabetes mellitus incidence among U. S. adults. Prev Med. 2001;32:33-39.

19. Levine J. Food industry marketing in elementary schools: implications for school health professionals. $J$ Sch Health. 1999;69:290-291. 